\title{
Metodologia interativa de ensino aprendizagem sobre manejo de pastagem
}

\section{Interactive teaching learning methodology on pasture management}

\author{
Fabiane Nunes Prates Camargo ${ }^{1}$ \\ Érico Marcelo Hoff do Amaral ${ }^{2}$ \\ Marcia Cristina Teixeira da Silveira ${ }^{3}$ \\ Daniel Portella Montardo ${ }^{4}$
}

\begin{abstract}
Resumo: Existem alguns gargalos que restringem o desenvolvimento da pecuária, como por exemplo, a baixa cobertura de assistência técnica, o que tem gerado problemas sérios de manejo e, consequentemente, produção animal a pasto abaixo do potencial. O que se observa é que como as pastagens são ecossistemas complexos e dinâmicos, as técnicas e as metodologias de avaliações precisam envolver vários aspectos de interação, como entendimento sobre solo, planta, animal e o meio ambiente. Deste modo, para se obter uma crescente evolução das atividades agropecuárias, é importante que sejam tomadas algumas iniciativas. Dentre elas, está a criação de estratégias que favoreçam o aprendizado na área, visto que o entendimento dos processos de interações entre os componentes do sistema tende a impactar positivamente no setor. Desta forma, o presente trabalho tem como objetivo propor uma metodologia de ensino, auxiliado pelo uso das Tecnologias de Informação e Comunicação, alinhadas as teorias de aprendizagem, que oportunize a estudantes, técnicos e produtores rurais a construção do conhecimento sobre os princípios básicos de manejo de pastagens. Com base no levantamento de requisitos realizado a partir de entrevistas com especialistas da área da agropecuária e estudo do referencial teórico foi desenvolvida uma metodologia de ensino interativa auxiliada por computador, apoiada na teoria de aprendizagem experencial de Kolb. Ademais, espera-se que esta metodologia contribua para o cumprimento dos Objetivos de Desenvolvimento Sustentável a nível global, destinados a assegurar padrões de produção e de consumo sustentáveis.
\end{abstract}

\section{Palavras-chave: Pecuária; Tecnologia de Informação e Comunicação; Tomada de decisão}

Abstract: There are some bottlenecks that restrict livestock development, such as low coverage of technical assistance, which has generated serious management problems and, consequently, low pasture livestock production. What is observed is that since pastures are complex and dynamic ecosystems, the techniques and methodologies of evaluations need to involve several aspects of interaction, such as understanding of soil, plant, animal and the environment. Thus, in order to achieve a growing evolution of agricultural activities, it is important that some initiatives are taken. Among them is the creation of strategies that favor learning in the area, since the understanding of the processes of interactions between the components of the system tends to

\footnotetext{
${ }^{1}$ Mestranda em Computação Aplicada - Instituto Federal de Educação, Ciência e Tecnologia Sul-rio-grandense / Docente.

\{fabianecamargo@ifsul.edu.br\}

${ }^{2}$ Universidade Federal do Pampa

\{erico.amaral@unipampa.edu.br\}

${ }^{3}$ Embrapa Pecuária Sul

\{marcia.c.silveira@embrapa.br\}

${ }^{4}$ Embrapa Pecuária Sul

\{daniel.montardo@embrapa.br\}
}

Rev. CCEI - URCAMP, V.24, n39 2019 (Submetido 22/11/2018; Aceito 31/10/2019)

DOI: https://doi.org/10.30945/ccei-v24i39.2726 
positively impact the sector. In this way, the present work aims to propose a teaching methodology, aided by the use of Information and Communication Technologies, aligned with learning theories, which will allow students, technicians and rural producers to build knowledge about basic management principles of pastures. Based on the survey of requirements made from interviews with specialists in the field of agriculture and the study of the theoretical framework, a methodology was developed for interactive teaching aided by computer, based on Kolb's theory of experiential learning. In addition, it is expected that this methodology contributes to the achievement of the Sustainable Development Goals at a global level, aimed at ensuring sustainable production and consumption patterns.

Keywords: Livestock; Information and Communication Technology; Decision-making.

\section{INTRODUÇÃO}

De acordo com a Organização das Nações Unidas no Brasil (ONU-BR) ${ }^{5}$, o conceito de desenvolvimento sustentável está relacionado à capacidade de atender as necessidades da geração atual, sem comprometer as gerações futuras de satisfazerem suas próprias necessidades. Neste sentido, em 2015, por ocasião da Cúpula das Nações Unidas sobre o Desenvolvimento Sustentável, que ocorreu na sede da ONU, líderes mundiais participaram do planejamento de uma nova agenda de desenvolvimento sustentável ${ }^{6}$, a Agenda 2030. Esta agenda é considerada um plano de ação universal, onde leva em conta a erradicação da pobreza em todas as suas formas e dimensões como o maior desafio global e um requisito indispensável para o desenvolvimento sustentável. Líderes da ONU acreditam que a disseminação da informação e das tecnologias da comunicação e interconectividade global tem um grande potencial para acelerar o progresso humano e para o desenvolvimento de sociedades do conhecimento, assim como a inovação científica e tecnológica.

No Brasil as áreas de pastagem se configuram na maior cultura agrícola do país, ocupando, segundo o último Censo Agropecuário ${ }^{7}$, mais de 150 milhões de hectares, ou seja, aproximadamente $20 \%$ da área cultivável do nosso território, contribuindo para transformação do país em um dos principais produtores agrícolas e pecuários do mundo. Neste cenário, embora o setor produtivo da região apresente uma série de peculiaridades que favorecem o desenvolvimento agropecuário, levantamentos citam que $80 \%$ das

\footnotetext{
${ }^{5}$ https://nacoesunidas.org/pos2015/agenda2030/

${ }^{6} \mathrm{https://nacoesunidas.org/pos2015/ \text {cupula/ }}$

${ }^{7}$ https://censos.ibge.gov.br/agro/2017/templates/censo agro/resultadosagro/estabelecimentos.html
}

Rev. CCEI - URCAMP, V.24, n39 2019 (Submetido 22/11/2018; Aceito 31/10/2019) 
pastagens se encontram em algum estado de degradação (FREITAS et al, 2016 apud PERON e EVANGELISTA, 2004) ou em áreas com solos degradados. Além disso, existem alguns gargalos que restringem o seu desenvolvimento, como por exemplo, a baixa cobertura de assistência técnica e o nível de instrução dos agropecuaristas, o que gera problemas de subpastejo, superpastejo pela dificuldade, por exemplo, de se saber o melhor momento de colocar ou retirar os animais na área.

Como as pastagens são ecossistemas complexos e dinâmicos (DA SILVA \& PEREIRA, 1997), as técnicas e as metodologias de avaliações também o são, o que torna o manejo do pasto alvo de pesquisas há muitos anos (SILVA, 2015). Até o final da década de 90, a maior preocupação era a geração de números que expressassem potencial produtivo das espécies e cultivares forrageiras e produção animal. Atualmente, os avanços observados na pesquisa científica referem-se principalmente à busca pelo entendimento dos processos visando um manejo ecologicamente correto, sustentável e que garanta alimento para a demanda crescente da população.

Deste modo, para se obter uma crescente evolução das atividades agropecuárias, é importante que sejam tomadas algumas iniciativas. Dentre elas, está a criação de estratégias que favoreçam o aprendizado na área, visto que o não entendimento dos processos envolvidos entre os componentes do sistema (solo-planta-animal-meio) tende a trazer severas limitações para o setor. Em se tratando de estratégias de aprendizagem, a necessidade de um maior envolvimento entre as áreas tecnológica e educacional é cada vez mais evidente (SOUSA, 2011). Segundo o autor, teorias e práticas associadas a informática na educação vêm repercutindo em nível mundial, justamente porque as ferramentas e mídias digitais oferecem à didática, objetos, espaços e instrumentos capazes de renovar as situações de interação, expressão, criação, comunicação, informação, e colaboração, tornando-a muito diferente daquela tradicionalmente fundamentada na escrita e nos meios impressos.

Ainda neste cenário, com avanço da tecnologia, a multimídia e a busca por métodos inovadores tem levado pesquisadores a desenvolverem diferentes sistemas de visualização de informação, como Realidade Aumentada (RA) e Realidade Virtual (RV). Segundo Romão (2013), tais tecnologias possibilitam a interação do usuário com os objetos virtuais, 
e vem sendo experimentada e utilizada por vários segmentos, com propósitos diversos. Inclusive, na na literatura podem ser encontrados uma série de trabalhos aplicados no contexto da agropecuária. Dentre eles, Nigan et al (2011), em seu artigo intitulado “Augmented Reality in agriculture” relata o desenvolvimento de um protótipo de sistema utilizando RA. Seu objetivo é ajudar agricultores na identificação de insetos e no manejo de pragas. Este sistema de identificação, sugere aos agricultores pesticidas e tratamentos adequados para os insetos. Azevedo (2014), no artigo intitulado " $O$ estudo da engine unity $3 D$ e blender aplicada em um observatório virtual” descreve a proposta de sistema que visa a imersão dos usuários em um ambiente virtual. O jogo fornece acesso às informações referentes aos cursos do UNIPAM, com o intuito de aumentar a visibilidade dos mesmos no cenário nacional. Por fim, o trabalho com o título "Hacia una Guía Digital Móvil para la identificación y manejo sustentable de los pastizales naturales”, desenvolvido por Frank et al (2017), trata de ferramentas para o gerenciamento sustentável de pastagens. O artigo apresenta um guia metodológico que estabelece locais de pastagem, de forma estruturada, com base em parâmetros de vegetação, porém, que necessita de do uso de um computador, o que dificulta seu uso no campo.

Baseado nesta dificuldade os autores apresentam os avanços no desenvolvimento de uma ferramenta digital para dispositivos móveis que implementa este guia para manejo de pastagens sustentável. Assim, estimulado pelos trabalhos correlatos, considerando o potencial uso das TIC no setor agropecuário, a importância da compreensão dos fundamentos do manejo do pasto e, o entendimento dos processos relacionados ao ecossistema como um todo, o presente trabalho visa apresentar uma proposta de metodologia de ensino interativa que contribua para a construção do conhecimento sobre manejo de pastagens.

Este artigo está organizado da seguinte forma. Na seção 2 é apresentada uma revisão de literatura abordando os conceitos básicos para realização deste trabalho. Na seção 3 são apresentados os procedimentos metodológicos da pesquisa. Na seção 4 é apresentada a descrição da metodologia de ensino proposta e, na seção 5 são descritos os resultados parciais. 


\section{REVISÃO DE LITERATURA}

Nesta seção são apresentados os princípios de manejo de pastagem, uma visão geral de como se dá o processo de ensino aprendizagem na visão de diferentes teórios e também são discutidas a importância e o potencial uso das TIC no ensino.

\subsection{PRINCÍPIOS DE MANEJO DE PASTAGEM}

Independentemente do tipo de animal que utilizará a pastagem, os princípios básicos de manejo são os mesmos (CARVALHO, 2004). Neste sentido, com o conhecimento dos processos é possível entender o crescimento das plantas forrageiras sob pastejo, desde a sua unidade básica até o acúmulo de massa na pastagem, entender a importância das tomadas de decisão quanto ao ajuste de carga, em função do crescimento do pasto, para então obter maior número de ciclos de pastejo, maior produção de forragem no período e, consequentemente, maior produção animal e do sistema como um todo. Desta forma, é possível ter idéia da complexidade do sistema de produção animal a pasto em função deste ser muito dinâmico e envolver vários componentes que interagem entre si.

A Figura 01, ilustra as inter-relações entre os componentes do ecossistema de pastagens. De acordo com Bueno et al (2016), seu funcionamento é regido por alguns princípios. O primeiro deles é que o sistema, para seu funcionamento, depende fundamentalmente de um fluxo de energia, onde a "entrada" depende da disponibilidade de radiação solar; O segundo, refere-se a caputura de energia incidente, que depende de uma superfície de captação, cujo tamanho e cuja eficiência de transformação da energia solar em energia química depende da disponibilidade de nutrientes assegurada pela absorção e reciclagem de nutrientes no sistema. E o terceiro princípio diz respeito ao pastej, pois afeta ambos os processos. O fluxo de energia ao "remover" superfícies de captação; o ciclo de nutrientes ao acelerar a mineralização e a disponibilidade de nutrientes através de sua retirada via produto animal.

Como pode ser visto, o manejo é o elo de ligação entre os componentes do sistema e, segundo Martins (2011), permite entender as possíveis relações de causa-efeito entre os

Rev. CCEI - URCAMP, V.24, n39 2019 (Submetido 22/11/2018; Aceito 31/10/2019)

DOI: https://doi.org/10.30945/ccei-v24i39.2726 
componentes atuantes no ecossistema de pastagens, de forma a gerar informações balisadoras de tomada de decisão mais acertadas. Neste sentido, é importante reconhecer que o manejo envolve vários processos, sendo necessário dentre outos fatores, avaliar as condições do clima, temperatura, radiação solar, precipitação, atentando para o tipo de solo e objetivos de cada sistema.

Figura 1 - Inter-relações entre os componentes do ecossistema pastagens.

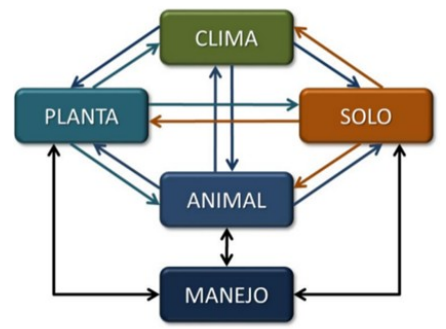

Fonte: Martins (2011)

Vale ressaltar que a metodologia de ensino, objeto de estudo deste trabalho, englobará mais detalhes dos conteúdos relacionados aos princípios de manejo de pastagens, utilizando as TIC para propiciar aos usuários uma melhor compreensão dos processos envolvidos, objetivando apoiar no âmbito ensino aprendizagem e contribuir na tomada de decisão. Em relação a aprendizagem, é importante compreender como se dá esse processo sob a óptica de diferentes teóricos e então verificar qual teoria de aprendizagem melhor atende o público alvo.

\subsection{PROCESSO ENSINO-APRENDIZAGEM}

O processo ensino-aprendizagem pode ser definido como um complexo sistema de interações comportamentais entre professores e alunos (KUBO et al, 2001). Segundo os autores, além de “ensino” e “aprendizagem”, como se fossem processos independentes da ação humana, há os processos comportamentais que recebem o nome de “ensinar” e de “aprender”, sendo importante o seu entendimento para o desenvolvimento de qualquer atividade voltada ao ensino. Entretanto, a forma como esses processos ocorrem variam con-

Rev. CCEI - URCAMP, V.24, n39 2019 (Submetido 22/11/2018; Aceito 31/10/2019)

DOI: https://doi.org/10.30945/ccei-v24i39.2726 
forme alguns teóricos. Cada um deles possui uma teoria acerca do tema e eles explicam, dentre outras coisas, como os indivíduos aprendem.

De acordo com Carvalho (2003), as teorias da aprendizagem apresentam contribuições à compreensão do processo de ensino e aprendizagem da criança/jovem ao adulto, considerando o desenvolvimento, a faixa etária e os aspectos psicossociais e cognitivos. Desta forma, nesta seção, serão apresentadas algumas teorias de aprendizagem que explicam como se dá esse processo na visão de alguns teóricos, como Piaget, Ausubel, Bruner, Vygotsky e Kolb. Autores como Brunner, Piaget, Ausubel seguem esta linha congnitivista, onde alguns deles são considerados construtivistas com ênfase na cognição, como é o caso de Brunner, Piaget, Ausubel e Novak ou enfatizam o aspecto cognitivo, como Kelly e Rogers (OSTERMANN, 2010).

Ausubel considera a aprendizagem significativa o fator mais importante num processo de ensino, pois se relaciona de maneira não arbitrária e substantiva a um aspecto relevante da estrutura cognitiva do indivíduo (MEC, 2010). A teoria da aprendizagem significativa de Ausubel, busca explicar como se dá o processo de aprendizagem, ou seja, como o indivíduo aprende, transforma, armazena e usa as informações aprendidas. Ela é baseada em dois aspectos, o primeiro refere-se ao envolvimento do aprendiz, isto é, sua disposição em aprender com significado. O segundo aspecto reside no fato do professor/instrutor conseguir identificar o que o aprendiz sabe sobre determinado tema, possibilitando o planejamento de estratégias adequadas para ensiná-lo e também a construção de ferramentas de ensino potencialmente criativas (NASCIMENTO et al 2017 apud NOVAK \& CAÑAS, 2006).

Segundo Oliveira et al (2016) Piaget é considerado o criador da epistemologia genética, para ele, o sujeito epistêmico expressa aspectos presentes em todas as pessoas, onde suas características conferem a todos os indivíduos a possibilidade de construir conhecimentos, desde o aprendizado mais simples até os mais elevados níveis de conhecimento. Para Piaget, o conhecimento não pode ser concebido como algo predeterminado desde o nascimento, nem como resultado do simples registro de percepções e informações, conhe- 
cimento resulta de uma inter-relação do sujeito com os objetivos que procura conhecer” (MOREIRA, 2009).

De acordo com Ostermann et al (2011), na teoria de Bruner, o que é importante em uma matéria de ensino é sua estrutura, suas ideias e relações fundamentais e estaca o processo da descoberta, através da exploração de alternativas e o currículo em espiral. O currículo em espiral significa que o aprendiz deve ter a oportunidade de ver o mesmo tópico repetidamente, em diferentes níveis de profundidade e, também, em diferentes modos de representação.

A importância da cultura, da linguagem e das relações sociais na teoria de Vygotsky fornece a base para uma educação em que o sujeito seja visto na sua totalidade (RODRIGUES et al, 2005). Ao entender o homem como um ser social, Vygotsky (1991) considera fundamental a interferência de pais, professores e colegas para o desenvolvimento do sujeito. O professor, especialmente, deve ser o estimulador da zona de desenvolvimento proximal, incentivando avanços que estão prestes a acontecer. A zona de desenvolvimento proximal é a distância entre o nível de desenvolvimento real, constituído por funções já consolidadas pelo sujeito, que lhe permitem realizar tarefas com autonomia, e o nível de desenvolvimento potencial, caracterizado pelas funções que, segundo Vygotsky, estariam em estágio embrionário e não amadurecidas (Vygotsky, 1989, p.97). Além disso, a concepção de Vygotsky sobre a relação desenvolvimento/aprendizagem apresenta um papel importante e imprescindível, remetendo a uma reflexão sobre o papel e a função das aprendizagens escolares no processo de desenvolvimento dos alunos.

De acordo com Pimentel (2017) a teoria da aprendizagem experencial criada por David Kolb (1984) atribui grande valor aos conhecimentos de caráter experiencial, partindo do princípio que todo desenvolvimento profissional prospectivo decorre da aprendizagem atual, assim como o desenvolvimento já constituído é imprescindível para o aprendizado. Isto significa que apropriar os saberes procedentes da experiência demanda processos contínuos de ação e reflexão. Para o autor, a aprendizagem experencial é vista como um processo por onde o conhecimento é criado através da transformação da experiência. Isto quer dizer que o que o conhecimento é um processo de transformação e que precisa ser continu- 
amente criado e recriado. A teoria de Kolb é composta por quatro etapas, são elas: Experiência Concreta (EC), Observação Reflexiva (OR), Conceituação Abstrata (CA) e Experimentação Ativa (EA). Esta teoria corrobora para o seu emprego nas ações voltadas para a criação de estratégias de aprendizagem por exemplo, de jovens e adultos, uma vez que reflete a qualificação quanto a competências, conhecimentos, sentimentos e postura ética relativos à profissão (PIMENTEL, 2007). Isto porque o foco da aprendizagem experiencial, é a interação entre o sujeito e a ação e sustenta as novas aprendizagens com base na experiência, ao mesmo tempo em que valoriza o contexto e a reflexão. Segundo Aviles et al (2017) nos últimos anos, o estudo dessas teorias tem contribuído na busca por resultados às demandas atuais da sociedade para construir uma cultura científica e tecnológica abrangente.

Dentre os fatores a se considerar, no contexto deste trabalho, é a busca na melhora do processo ensino-aprendizagem e, também, como se dá o processamento da informação para a tomada de decisão, uma vez que a metodologia de ensino proposta vai ao encontro da criação de estratégias que favoreçam o aprendizado e axilie no processo de tomada de decisão. Neste sentido, o uso das TIC no ensino pode contribuir nesse processo, conforme é apresentado na próxima seção.

\subsection{Tecnologias de Informação e Comunicação (TIC) aplicadas ao ensino}

As TIC são um conjunto de recursos tecnológicos integrados entre si, que proporcionam por meio de software e telecomunicações, a automação e comunicação dos processos de negócios, da pesquisa científica e de ensino e aprendizagem (Oliveira et al, 2015). O autor ainda afirma que a inserção das TIC no cotidiano escolar anima o desenvolvimento do pensamento critico criativo e a aprendizagem cooperativa, uma vez que torna possível a realização de atividades interativas.

Neste contexto, percebe-se a importância e o potencial uso dessas tecnologias, onde seu surgimento é caracterizado pelo seu alcance global, pela integração de todos os meios

Rev. CCEI - URCAMP, V.24, n39 2019 (Submetido 22/11/2018; Aceito 31/10/2019)

DOI: https://doi.org/10.30945/ccei-v24i39.2726 
de comunicação e pela interatividade que está mudando e mudará para sempre a cultura das pessoas(CASTILHO apud CASTELLS (2003). Além do que, a utilização das TIC tem se mostrado um processo irreversível, podendo auxiliar na formação do ser humano, por meio da exploração de práticas pedagógicas mais recentes (ALBERTIN; MOURA, 1994). Contudo, em se tratando de educação, o emprego de algumas ferramentas de Tecnologia de Informação (TI) por si só não garantem o aprendizado (Silva, 2016). Para que seu uso seja eficiente e o aprendizado realmente ocorra, vários são os fatores que precisam ser considerados na prática. Um deles são as teorias de aprendizagem que estão atreladas nesse processo, pois darão o embasamento teórico científico em relação as aspectos pedagógicos, uma vez que estão relacionados a área que estuda como se dá o ensino/ aprendizagem e os problemas relacionados ao seu desenvolvimento como um todo.

De acordo com Resnick (2004) muitas das melhores experiências de aprendizado ocorrem quando os estudantes estão envolvidos em atividades lúdicas. Neste sentido, um campo que ganhou bastante popularidade nos dias atuais é a RV. Além disso, nos últimos anos houve uma crescente demanda por tecnologias para apoiar o processo de ensino/aprendizagem, como é o caso dos ambientes virtuais. Isso ocorreu devido à capacidade destes ambientes de gerarem mundos sintéticos, ou seja, que permitem a imersão, navegação e interação por meio da exploração dos sentidos básicos do corpo (SCAMATI et al, 2015). A Realidade Virtual (RV), para Sobrinho (2011), pressupõe o uso de sistemas computacionais sensíveis ao posicionamento do usuário no espaço e que possibilitam sua interatividade com o ambiente. Esses sistemas, por sua vez, fornecem algum tipo de retorno sensorial ao usuário, causando a sensação de se estar imerso, em algum grau, nesse mundo simulado ou virtual. Além disso, o mesmo autor define a RV como um conjunto de recursos e técnicas que visam criar ambientes virtuais com alto grau de envolvimento dos sentidos, de forma a criar e potencializar a sensação de imersão no ambiente. Dentre suas características técnicas estão o uso de computação de alto desempenho, processamento em tempo real e alto grau de interação.

Outro recurso que vem ganhando cada vez mais espaço com o avanço da tecnologia é a Realidade Aumentada (RA). Diferentemente da RV, na qual o usuário é imerso em um 
ambiente, a RA é um sistema que reune objetos reais e virtuais em um ambiente real (ROMÃO 2013 apud AZUMA 2001). Para o entendimento desse sistema é importante compreender outros conceitos atrelados a ele, o da multimília e a da hipermídia. Multimídia, segundo Fluckiger (1995) é o campo interessado na integração controlada por computador de textos, gráficos, imagens, vídeos, animações, sons e qualquer outro meio onde todo tipo de informação pode ser representada, armazenada, transmitida e processada digitalmente.

Já em publicações mais recentes, Amorim et al (2010) define multimídia como o uso combinado de várias mídias, como som e vídeo com imagens em movimento em aplicações computacionais. Já a hipermidia, segundo Machado (2001) é uma forma combinatória, permutacional e interativa de multimídia, em que textos, sons e imagens estão ligados entre si por elos probabilísticos e móveis, que podem ser configurados pelos receptores de diferentes maneiras, de modo a compor obras instáveis, em quantidades infinitas. Neste contexto, esses recursos e ambientes surgem como uma ótima alternativa para criação de espaços de observação e interação, possibilitando a realização de uma série de atividades, entre elas, atividades voltadas para o ensino e treinamento, além de poder ser aplicada em qualquer área, inclusive na agropecuária. Neste contexto, dentre as tecnologias a serem aplicadas na metodologia de ensino estão: animações, imagens em 360 graus, sons e simuladores virtuais.

\section{PROCEDIMENTOS METODOLÓGICOS}

Quanto a natureza, esta pesquisa é classificada como uma pesquisa original, pois busca apresentar conhecimento novo a partir de observações e teorias construídas para explicá-lo (WAZLAWICK, 2010). Já em relação aos objetivos a pesquisa é considerada exploratória, havendo o estudo de teorias e técnicas que levem ao desenvolvimento de uma metodologia de ensino para que possa ser aplicado e avaliado. Sob o ponto de vista dos procedimentos, este trabalho envolve uma pesquisa bibliográfica e experimental, pois o seu desenvolvimento implica o estudo de artigos, teses, livros e outras publicações. Além disso, experimentos serão realizados em função da aplicação, testes e validação da metodologia de ensino. 
A pesquisa abrangeu as bases de dados eletrônicas consideradas como sendo as fontes científicas mais relevantes. As bases de dados eletrônicas selecionadas foram: IEEE, SciELO e Banco de Teses da Capes. Os tipos de trabalhos considerados foram: teses, dissertações, monografias, artigos de revisão e artigos publicados em conferências ou periódicos. Primeiramente, foi realizada uma revisão bibliográfica acerca dos assuntos relacionados ao tema deste trabalho, como as teorias de aprendizagem, manejo de pastagens, TIC aplicada ao ensino e TIC aplicada a agropecuária e trabalhos correlatos.

A partir da revisão bibliográfica foi elaborado o modelo da metodologia de ensino, que está descrito na próxima seção. Este modelo foi apresentado a pesquisadores da área de manejo de pastagem da Embrapa Pecuária Sul e que já possuem alguma experiência no oferecimento de capacitações para produtores rurais da região. Tal ação visou a verificação por parte de especialistas, se o modelo poderá ou não atender aos objetivos deste trabalho. Na etapa seguinte, foi realizado o levantamento de requisitos do software através de entrevistas semiestruturadas e brainstorming, onde foram coletados dados e informações indispensáveis para o seu desenvolvimento, como público alvo e conteúdos a serem abordados na ferramenta. Este levantamento foi feito com pesquisadores da Embrapa, que desenvolvem pesquisas em bovinocultura de corte e leite, ovinocultura e forrageiras nos Campos Sul Brasileiros, compreendidos pelos Estados do Rio Grande do Sul, Santa Catarina e Paraná (EMBRAPA, 2018).

Os testes do sistema serão executados com base em um planejamento realizado em paralelo com o desenvolvimento para verificar se os resultados obtidos estão de acordo com o esperado. Para tal, será utilizada a técnica de teste funcional, que é aplicável a todos os níveis de teste (PRESSMAN, 1995). Está técnica será empregada em quatro níveis, a saber: teste de unidade, integração, teste de sistema e teste de aceitação. Os três primeiros serão realizados pela desenvolvedora da aplicação e o último, teste de aceitação, será realizado pelos pesquisadores da Embrapa Pecuária Sul, que participaram da análise de requisitos, para verificar se cada módulo do software implementado atende ao solicitado.

Rev. CCEI - URCAMP, V.24, n39 2019 (Submetido 22/11/2018; Aceito 31/10/2019)

DOI: https://doi.org/10.30945/ccei-v24i39.2726 
O sistema será disponibilizado na web e, posteriormente, em parceria com pesquisadores da Embrapa Pecuária Sul, será realizado um estudo de caso, onde a metodologia será testada e avaliada. A ferramenta de software será avaliada de acordo com os seguintes critérios: aceitação, conhecimento e usabilidade. Para o teste de aceitação será utilizado o Modelo de Aceitação de Tecnologia (TAM), apresentado por Fathema e Sutton (2013). Já para o teste de usabilidade será utilizado o método SUS. Já a avaliação dos conhecimentos dos usuários será realizada em dois momentos distintos. O primeiro, logo no início do processo, com a aplicação de uma avaliação diagnóstica e o segundo, ao final, com a aplicação de uma avaliação somativa.

\section{RESULTADOS PARCIAIS}

O modelo que ilustra a metodologia de ensino proposta, foi elaborado a partir da revisão bibliográfica e levantamento de requisitos e está representado na Figura 2. Como pode ser visto na imagem, a metodologia envolve a construção de um sistema computacional alinhado às teorias de aprendizagem de Kolb, buscando o uso combinado de uma série de tecnologias, recursos multimídias, técnicas de gamificação e atividades que auxiliem o público-alvo no entendimento dos processos e na busca de uma aprendizagem significativa acerca do manejo de pastagem.

Figura 2 - Modelo da Metodologia de Ensino

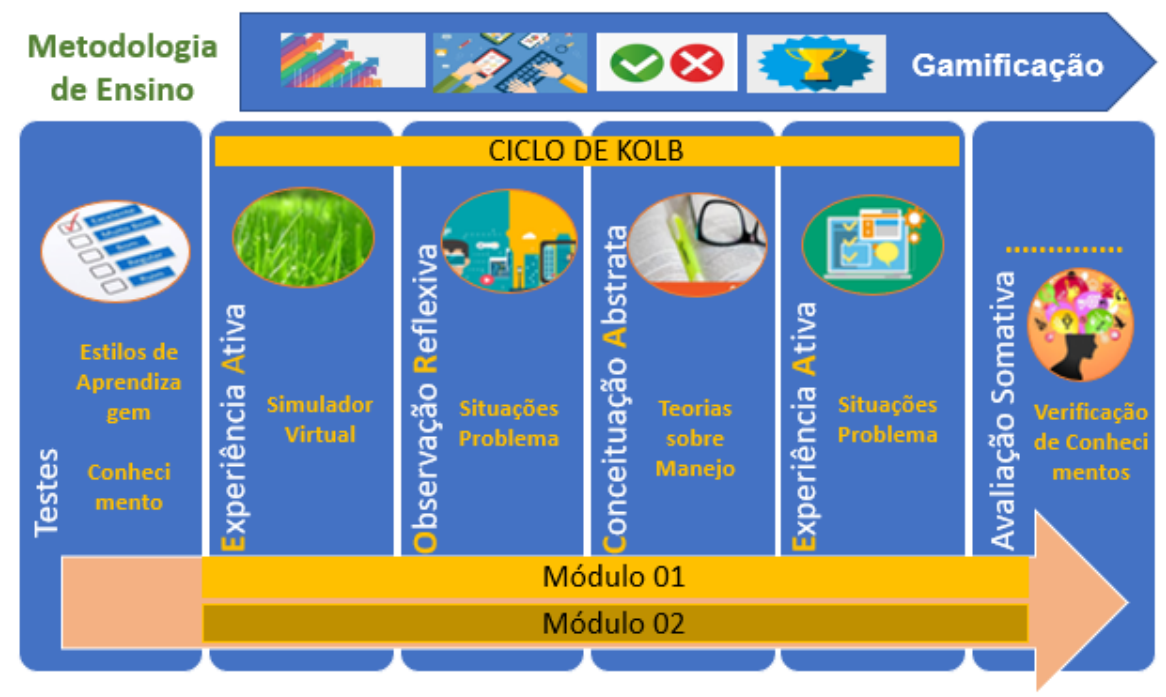

Fonte: autoria própria 
Na fase de levantamento de requisitos foi verificada a necessidade de um sistema que permita a estudantes, técnicos e produtores rurais entenderem desde o crescimento e desenvolvimento de plantas individuais, passando pelo acúmulo de forragem no pasto e aspectos relativos ao uso desse pasto pelos animais em pastejo, de forma a se ter ideia do comportamento da planta sob pastejo e da importância do melhor uso de estratégias de manejo para beneficiar planta e animais; deve mostrar como se dá o desenvolvimento de uma unidade básica de planta forrageira hipotética (desenvolvimento do perfilho); mostrar o início do perfilhamento de cada planta individual; mostrar o crescimento de planta individual sendo responsável pelo acúmulo de forragem no pasto (curva de acúmulo de forragem do estabelecimento ao momento do pastejo); demonstrar que a partir de um determinado momento a planta não mais investe em folhas e sim em outras estruturas que não são de interesse para o consumo animal; apontar a importância de saber o momento de se interromper esse crescimento do pasto; demonstrar como que os fatores do meio (luz, temperatura, precipitação, adubação, etc) podem interferir no crescimento do pasto.

No levantamento de requisitos foi definido que o sistema será composto por dois módulos. O primeiro módulo contemplará conteúdos sobre noções básicas de manejo aplicáveis a todas as pastagens e que inclui: crescimento e desenvolvimento da unidade básica da planta; acúmulo de forragem no pasto e aspectos relativos ao uso do pasto. Já o segundo módulo, conterá informações específicas acerca do manejo do capim Sudão. Ambos os módulos foram projetados de forma que atendam as etapas do ciclo de aprendizagem de Kolb. Neste sentido, ao iniciar o uso do sistema o usuário passará por dois testes, compostos por questões objetivas. O primeiro fará a identificação de estilo de aprendizagem. O Segundo fará a verificação do nível de conhecimento do usuário sobre as teorias de manejo de pastagem. Deste modo, o sistema poderá guiar o usuário durante as atividades ao longo do uso do sistema, passando por uma EA, OR, CA e EA e, além disso, atendendo suas características individuais e respeitando seu estilo de aprendizagem.

Como se trata de uma metodologia de ensino, algumas atividades formativas e somativas estão previstas. Por atividade formativa, neste caso, entende-se, a aplicação de alguns questionamentos e atividades dentro de cada etapa, seguindo o ciclo de aprendizagem experencial de Kolb (1988). Na Observação Reflexiva, por exemplo, é prevista a

Rev. CCEI - URCAMP, V.24, n39 2019 (Submetido 22/11/2018; Aceito 31/10/2019) 
identificação de elementos, construção de associações e agrupamentos entre os fatos perceptíveis da experiência. Essas atividades formativas servem de base para identificar como o processo de aprendizagem tem acontecido, bem como permitir redirecionamentos e/ou indicações necessárias no sistema, através de um método de ensino guiado, ou seja, onde o sistema indica ao usuário os passos a seguir no sistema. Além disso, técnicas de gamificação com a finalidade de engajar e motivar os usuários para a aprendizagem serão aplicadas no sistema, como definição de regras para mudança de nível dentro dos módulos, feedback automático das atividades realizadas e entrega medalhas. As avaliações somativas previstas na metodologia, são aquelas em que o usuário passará por uma verificação dos conhecimentos construídos ao longo das atividades realizadas dentro do ciclo de aprendizagem (EA, OR, CA e EA).

\section{CONSIDERAÇÕES FINAIS}

A nível científico, espera-se que esta proposta seja um instrumento tecnológico para auxiliar no processo de ensino/aprendizagem sobre os princípios básicos de manejo de pastagem e, desta forma, aprimore as competências de produtores rurais, técnicos e estudantes da área, permitindo a tomada de decisão efetiva e atendendo os ODS, destinados a assegurar padrões de produção e de consumo sustentáveis a nível global. Já a nível tecnológico, busca-se que os recursos desenvolvidos permitam potencializar a construção do conhecimento sobre o tema, oferecendo uma interface acessível, interativa e amigável ao público alvo.

\section{REFERÊNCIAS}

AZEVEDO, J. D. O estudo da engine unity 3D e blender aplicada em um observatório virtual. Revista Perquirere, 11(1): 130-143, jul. 2014

BUENO, C. S, PEREIRA, E. T. P. Produção e Conservação de Forragens. Universidade de São Paulo. Faculdade de Zootecnia e Engenharia de Alimentos - 2016.

CARVAlHO, P. C. F., Princípios Básicos do Manejo das Pastagens. In: Octaviano Alves Pereira Neto. (Org.). Práticas em ovinocultura: ferramentas para o sucesso. 1 ed. Porto Alegre: Gráfica e Editora Solidus Ltda., 2004 , v. 1 , p. 9-14. 
CASTILHO, L. B. O uso da tecnologia da informação e Comunicação (TIC) no processo de ensino aprendizagem em Cursos Superiores. Dissertação (Mestrado Profissional em Sistemas de Informação e Gestão do Conhecimento ) Universidade FUMEC 2013-2015.

EMBRAPA. Sistema de produção de leite com recria de novilhas em sistemas silvipastoris. sistema de Produção, No. $\quad$ N. $\quad$ ISSN 1678-314X. $<$ https://sistemasdeproducao.cnptia.embrapa.br/FontesHTML/Leite/LeiteRecriadeNo vilhas/instalacoes.htm > Acesso em: 10 Maio 2018.

FATHEMA, N., SUTTON, K. Factors influencing faculty members’ Learning Management Systems adoption behavior: An analysis using the Technology Acceptance Model. International Journal of Trends in Economics Management \& Technology, Vol. II(vi), 2013.

MOREIRA, M. A. Teorias de Aprendizagem. 3. Ed. São Paulo: Editora Pedagógica e Universitária, 2009.

PEREIRA, D. M., SILVA, G. S. As Tecnologias de Informação e Comunicação (TIC) como aliadas para o desenvolvimento. Periódicos da Universidade Estadual do Sudoeste da Bahia. Disponível em:

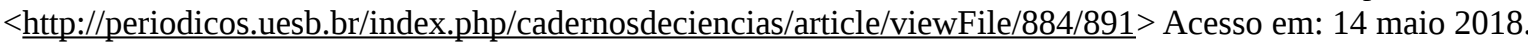

NIGAN, A. KABRA, P.; D OKE, P. Augmented Reality in agriculture. IEEE 7th International Conference on Wireless and Mobile Computing, Networking and Communications, p. 445 - 448, 2011.

OLIVEIRA, M. R., SILVA, G. C., LIMA J. R., SANTOS, J. Dr. G. As contribuições da Teoria Piagetiana para o processo de ensino aprendizagem.

OSTERMANN, F. CAVALCANTI, C. J. H. Teorias de Aprendizagem. Porto Alegre: Evangraf; UFRGS, 2011

PIMENTEL, A teoria da aprendizagem experiencial como alicerce de estudos sobre desenvolvimento profissional. Estudos de Psicologia - Universidade Federal do Rio Grande do Norte. 2007.

RESNICK, M.. "Edutainment? No thanks. I prefer playful learning." Associazione Civita Report on Edutainment 14 (2004):1-4.

ROMÃO, V. P. A., GONÇALVES, M. Realidade Aumentada: conceitos e aplicações no Design.Unoesc \& Ciência - ACET, Joaçaba, v. 4, n. 1, p. 23-34, jan./jun. 2013

SILVA, Flávia Daniely de Oliveira. O Professor frente as Novas Tecnologias e as Implicações no trabalho docente. II Congresso Nacional de Educação, 2016.

WAZLAWICK , R. S. Uma Reflexão sobre a Pesquisa em Ciência da Computação à Luz da Classificação das Ciências e do Método Científico. Revista de Sistemas de Informação da FSMA n. 6 (2010) pp. 3-10.

Rev. CCEI - URCAMP, V.24, n39 2019 (Submetido 22/11/2018; Aceito 31/10/2019)

DOI: https://doi.org/10.30945/ccei-v24i39.2726 